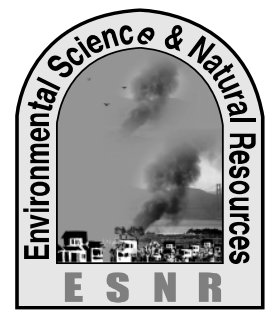

\title{
Effect of Different Plucking Systems on Yield and Root Starch Reserve in Two Cultivars of Tea (Camellia sinensis L.)
}

\author{
T. Ahmed ${ }^{1 *}$, W. A. J. M. De Costa ${ }^{2}$ and M. A. Wijeratne ${ }^{3}$ \\ ${ }^{1}$ Bangladesh Tea Research Institute, Srimangal - 3210, Moulvibazar \\ ${ }^{2}$ Department of Crop Science, Faculty of Agriculture, University of Peradeniya, Sri Lanka \\ ${ }^{3}$ Tea Research Institute, Low-Country Station, Ratnapura, Sri Lanka \\ *Corresponding author: toufiqtea@yahoo.com
}

\begin{abstract}
A study was carried out to monitor the effect of different plucking systems on root starch reserve and yield of tea in two cultivars (drought tolerant TRI2025 and moderately drought tolerant TRI2026). Depending on the severity of plucking, four plucking systems were used as treatments namely, mother-leaf plucking, fish-leaf plucking, janam-leaf plucking and estate practice. The cultivar TRI2026 showed significantly higher yield than the drought tolerant cultivar TRI2025. Estate practice produced greater yield in TRI2025 than the other treatments, while in TRI2026 the highest yield was found in fish-leaf plucking system. Although cultivars had no significant effect on root starch reserves, however significantly different found in treatments. About one year after commencing the experiment, for both cultivars higher root starch observed under mother-leaf plucking and the lowest was in janam-leaf plucking.
\end{abstract}

Key words: Root starch, Severity of plucking, Tea cultivar and Yield

\section{Introduction}

Plucking in tea is the removal of tender and apical portions of secondary and higher order shoots which are subsequently processed to give the commercial product. In tea, the plucking of shoot acts as a stimulus for further shoot production by temporarily destroying apical dominance (Portsmouth and Rajiah, 1957). The axillary bud immediately below the point of plucking is activated and develops into a new shoot. Yield components of tea are the number of shoots per unit land area, shoot growth rate, shoot size and mean weight of shoots at harvest (Tanton, 1992). Of these components, shoot density is the major yield factor which determines more than $80 \%$ of the variation in yield of tea (Wijeratne, 2001). Visser (1960) observed that hard plucking caused quicker production of many shoots of harvestable size, production of a large number of shoots per unit area of bush and enhanced photosynthetic efficiency due to better light penetration. Green (1965) observed that hard plucking may deleterious if continued to a constant height because it causes the deterioration of the bush. Severity of plucking determines the post-harvesting point of a shoot. Different plucking systems are followed in different agro-climatic regions due to difference in the rate of shoot growth. Some follow mother-leaf plucking, while others adopt fish-leaf and janam-leaf plucking. Mother-leaf plucking was the standard estate practice in Sri Lanka (Portsmouth, 1957) but now the estate practice plucking system (a combination of mother-leaf plucking and fish-leaf plucking) is popular while in North-East India janam-leaf plucking is practiced due to high growth rate (Wettasinghe et al., 1981). The appropriate plucking system may vary from cultivar to cultivar. In order to maximize the crop production and for the sustainability of a bush, it is necessary to find out the appropriate plucking system for a particular tea field. Pruning is a general practice in tea to maintain its vegetative phase and to keep its form and height convenient for harvesting which will ensure maximum production as well. Pruning removes leaves from the tea bush which produce carbohydrates through the photosynthesis. Root starch reserves play an important role in recovery after pruning. Wijeratne et al. (2002) stated that 1-2 months of resting before pruning increased root reserves and the level of root reserves declined rapidly soon after pruning. Therefore, this study was undertaken to know the effects of different standard of plucking on yield and starch reserves in roots of two tea cultivars.

\section{Materials and Methods}

The study was carried out at the Tea Research Institute, Low Country Station, Ratnapura $\left(6^{\circ} 40^{\prime} \mathrm{N}, 80^{\circ} 25^{\prime} \mathrm{E}\right.$ and $30 \mathrm{~m}$ amsl) and data were collected about a period of one year (from March 2011 to February 2012). The experiment was consisted of a two-factor factorial treatment structure. The treatment factors were a) two tea cultivars and $b$ ) four plucking standards. The two tea cultivars, drought tolerant TRI2025 (Assam-type) and moderately drought tolerant TRI2026 (China-type) were used. The four different standard of plucking were mother-leaf plucking (shoot is plucked leaving the oldest normal leaf), fish-leaf plucking (plucking to the fish-leaf), janam-leaf plucking (plucking below the fishleaf) and estate practice. In the estate practice, about 60$75 \%$ of tea crop shoots were plucked to the fish-leaf and the balance to the mother leaf (Wettasinghe et al., 1981). There were four replicate plots for each cultivar $\mathrm{x}$ plucking standard treatment combination. Altogether there were 32 experimental plots and each plot having 10 bushes were demarcated. So, the experimental area was laid in a randomized complete block design. Tea bushes were 11 years old with double hedge spacing $(0.6 \mathrm{~m} \times 0.9 \mathrm{~m} \times 1.5 \mathrm{~m})$ and were in the third year of its pruning cycle. Application of fertilizers and cultural practices were carried out according to the recommendations of TRI, Sri Lanka.

Plucking was done in the morning, on weekly rounds, for estimation of the plot yield $\left(\mathrm{g} \mathrm{plot}^{-1}\right)$. For tea yield, fresh weight of each plot was multiplied by the factor of 0.2 (De Costa et al., 2007) which was the plot yield (g plot $^{-1}$ ) and it was used to extrapolate the yield in $\mathrm{kg} \mathrm{ha}^{-1}$. 
Before plucking, harvesting shoot density (No. $\mathrm{m}^{-2}$ ) was measured from each plot by using a wooden frame.

Starch reserves (hot water soluble) in roots of about pencil thickness were measured adopting colorimetric quantifications (Krishnapillai et al., 1992). As root starch reserves are highly likely influenced with the response of different standards of plucking, root starch content in all treatment combinations were assessed at three-month intervals throughout the experimental period.

\section{Results and Discussion}

The harvested shoot density was highly significant for cultivars, treatments and between their interaction effects. Greater number of shoots $\mathrm{m}^{-2}$ were harvested in TRI2026 (237) than TRI2025 (212). Similar findings observed by Stephens and Carr (1994) that shoot population density of tea almost depended on its genetic makeup. In cultivar TRI2025, greater number of harvested shoots $\mathrm{m}^{-2}$ were observed in estate practice (217) which was statistically similar with fish-leaf plucking and mother-leaf plucking but different with janam-leaf plucking. However for cultivar TRI2026, greater number of harvested shoots $\mathrm{m}^{-2}$ observed in fishleaf plucking (243) which was similar with janam-leaf plucking and estate practice but significantly different with mother-leaf plucking (Fig. 1).

(a)

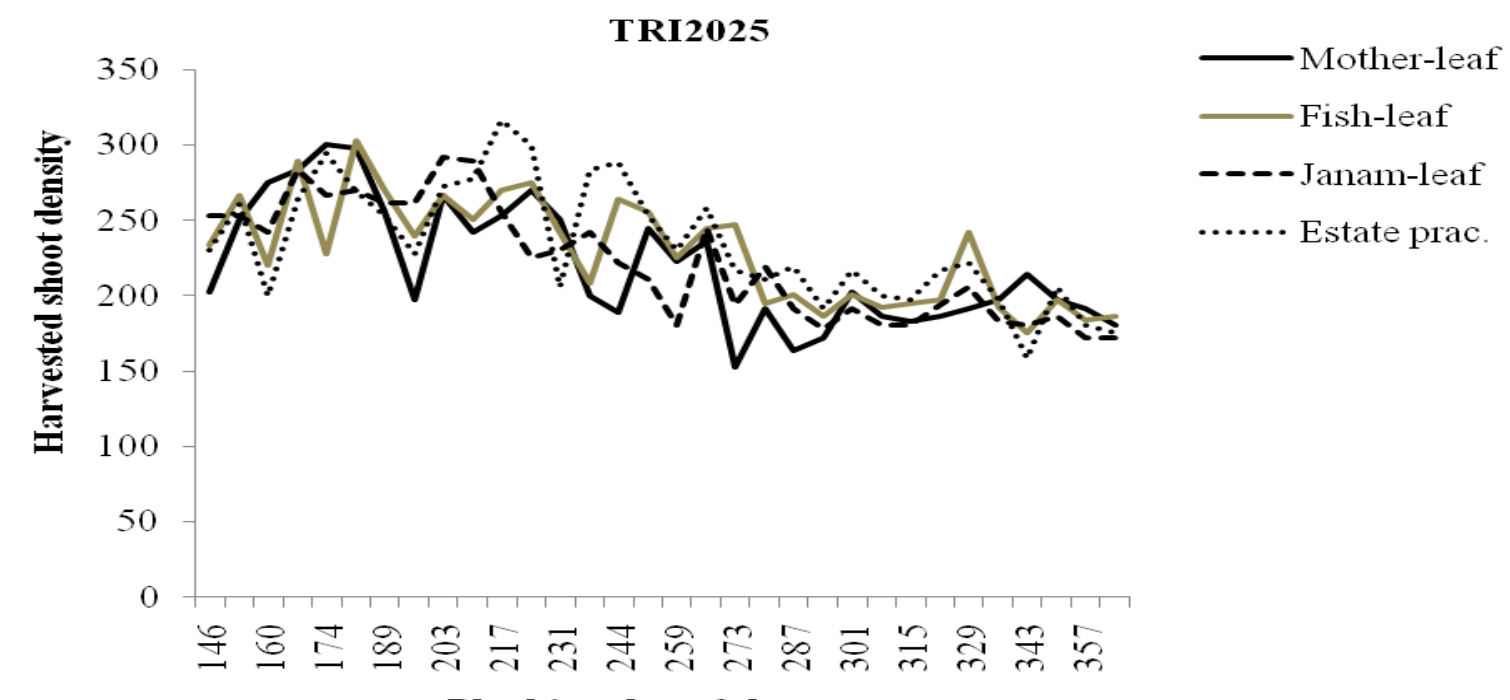

Plucking day of the year

(b)

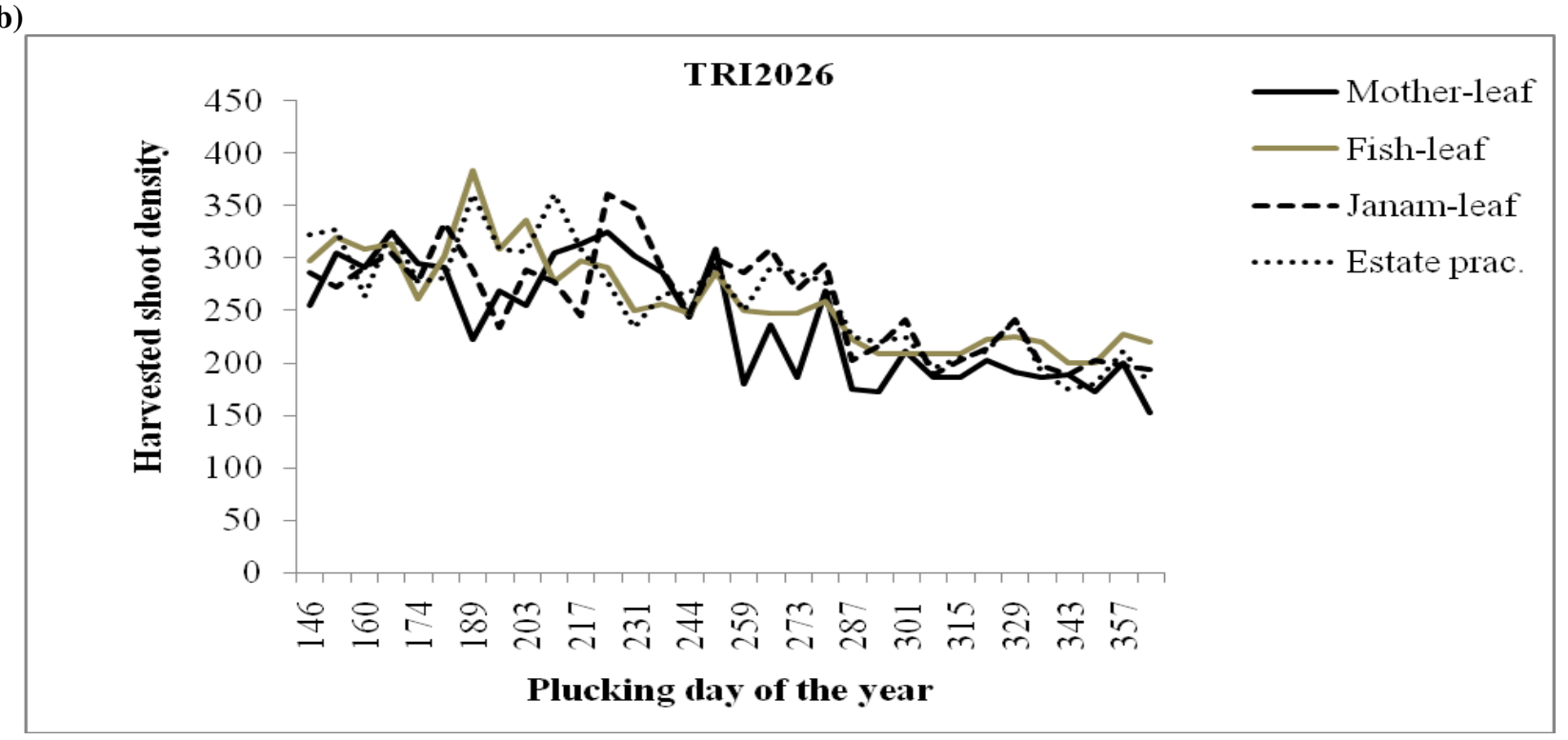

Fig. 1. Harvested shoot density $\left(\right.$ No. $\mathrm{m}^{-2}$ ) for different levels of plucking in (a) TRI2025 and (b) TRI2026 at different plucking days of the year

There was no significant effect for the interaction between cultivar and treatment on made tea yield at $5 \%$ level of probability. Moreover, treatment effect was also non-significant on made tea yield as a separate tea cultivar TRI2025 and TRI2026. In TRI2025, among the treatments estate practice gave the highest yield $(3,653$ 
$\pm 424 \mathrm{~kg} \mathrm{ha}^{-1}$ ) and the lowest yield was in janam-leaf plucking $\left(2,854 \pm 184 \mathrm{~kg} \mathrm{ha}^{-1}\right)$. Whereas in TRI2026, the highest and the lowest yield recorded in fish-leaf plucking $\left(4,081 \pm 530 \mathrm{~kg} \mathrm{ha}^{-1}\right)$ and mother-leaf plucking $\left(2,888 \pm 265 \mathrm{~kg} \mathrm{ha}^{-1}\right)$ respectively, as showed in the Fig. 2. For overall analysis, between the two cultivars greater yield observed in TRI2026 $\left(3,652 \pm 173 \mathrm{~kg} \mathrm{ha}^{-1}\right)$ and the lower in TRI2025 (3,234 $\left.\pm 265 \mathrm{~kg} \mathrm{ha}^{-1}\right)$. Having greater harvested shoot density, the cultivar TRI2026 produced $13 \%$ more made tea yield than the drought tolerant TRI2025. Similar findings observed by Stephens and Carr (1994) that shoot population density of tea almost depended on its genetic makeup which considered as the major yield component of tea. Wickramaratne (1981) showed differences in shoot dry weight due to cultivar differences in shoot characters like intermodal length and leaf size. From another research findings, Wijeratne (1994) stated that the drought tolerant cultivar produced less number of harvested shoot than the drought susceptible one and ultimately affected on yield. In TRI2025, the lowest yield observed in janam-leaf plucking which supported with the findings of Wettasinghe et al. (1981) who stated that increasing severity of plucking increased the harvest index up to a certain period after which it will be decreased due to aging of maintenance foliage. Moreover, present study showed that in both cultivars, mother-leaf producing lower yield and it was more pronounce in TRI2026 than TRI2025. The main reason of low yield in mother-leaf plucking was due to its lower number of plucking point per unit land area.

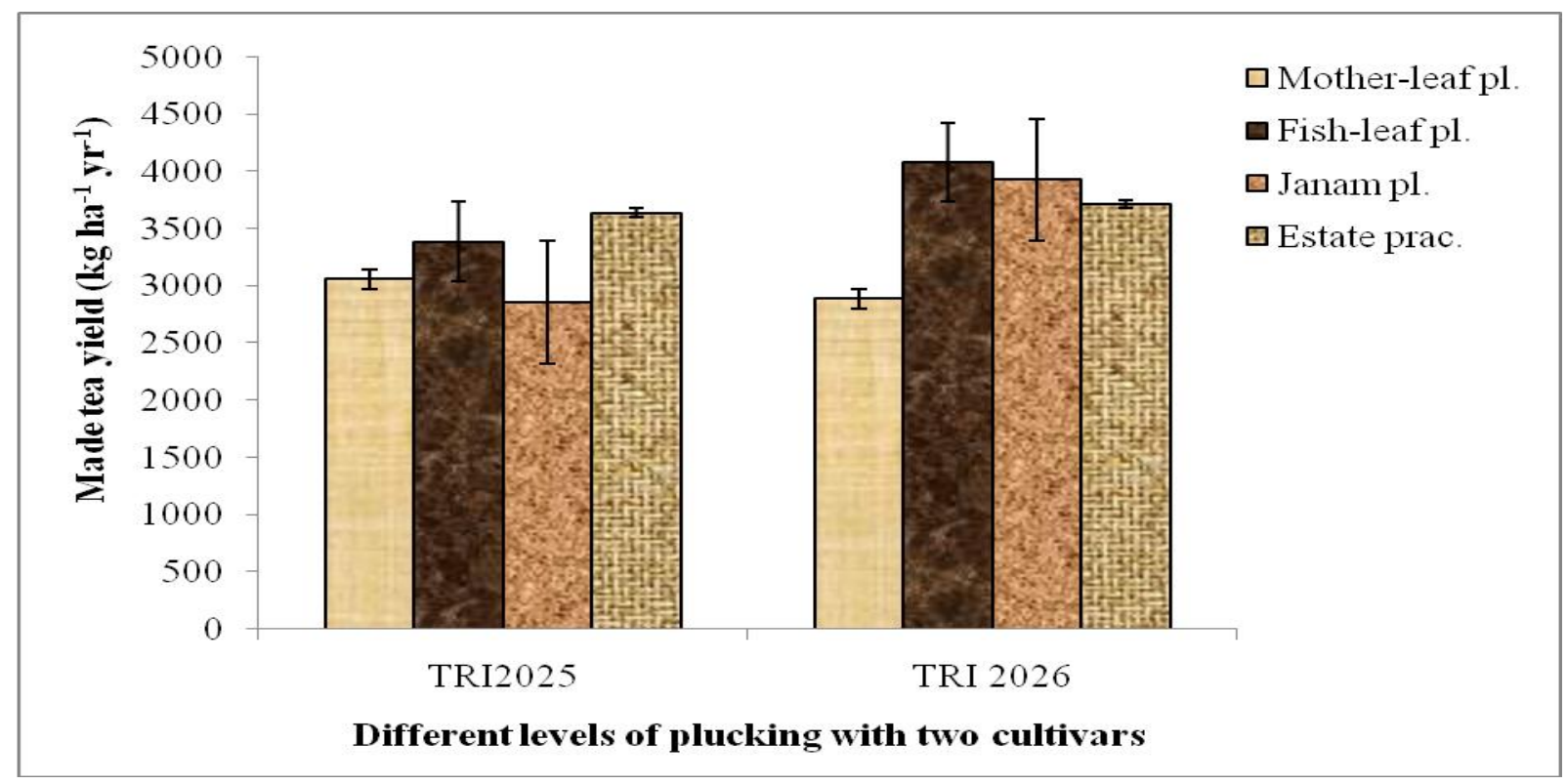

Fig. 2. Variation of made tea yield due to treatments in two tea cultivars

The experiment continued about the period of one year and the starch reserves of root was measured at three months intervals. The interaction effect between cultivar X treatment and the cultivar effect separately was non-significant at 5\% level of probability. However for both cultivars, the treatment effect was nonsignificant on root starch for all measuring days except the final one. At the final observation, in TRI2025 higher and lower level of starch reserves of roots were recorded from mother-leaf plucking $(9.1 \pm 1.0 \%)$ and janam-leaf plucking $(6.0 \pm 0.6 \%)$, and in case of
TRI2026, that was in estate practice $(8.5 \pm 0.8 \%)$ and janam-leaf plucking $(5.3 \pm 0.8 \%)$ presented in Fig. 3(a) and 3 (b). From the above findings, it is evident that harder plucking systems are associated with yield increments but it decreases the production of nonharvestable vegetative parts viz. maintenance leaves and starch reserves of roots. The observation is partially supported by Wettasinghe et al. (1981) who stated that in the case of janam-leaf plucking the decrease in nonharvestable growth is large, and greater than that expected on account of increased crop. 
(a)

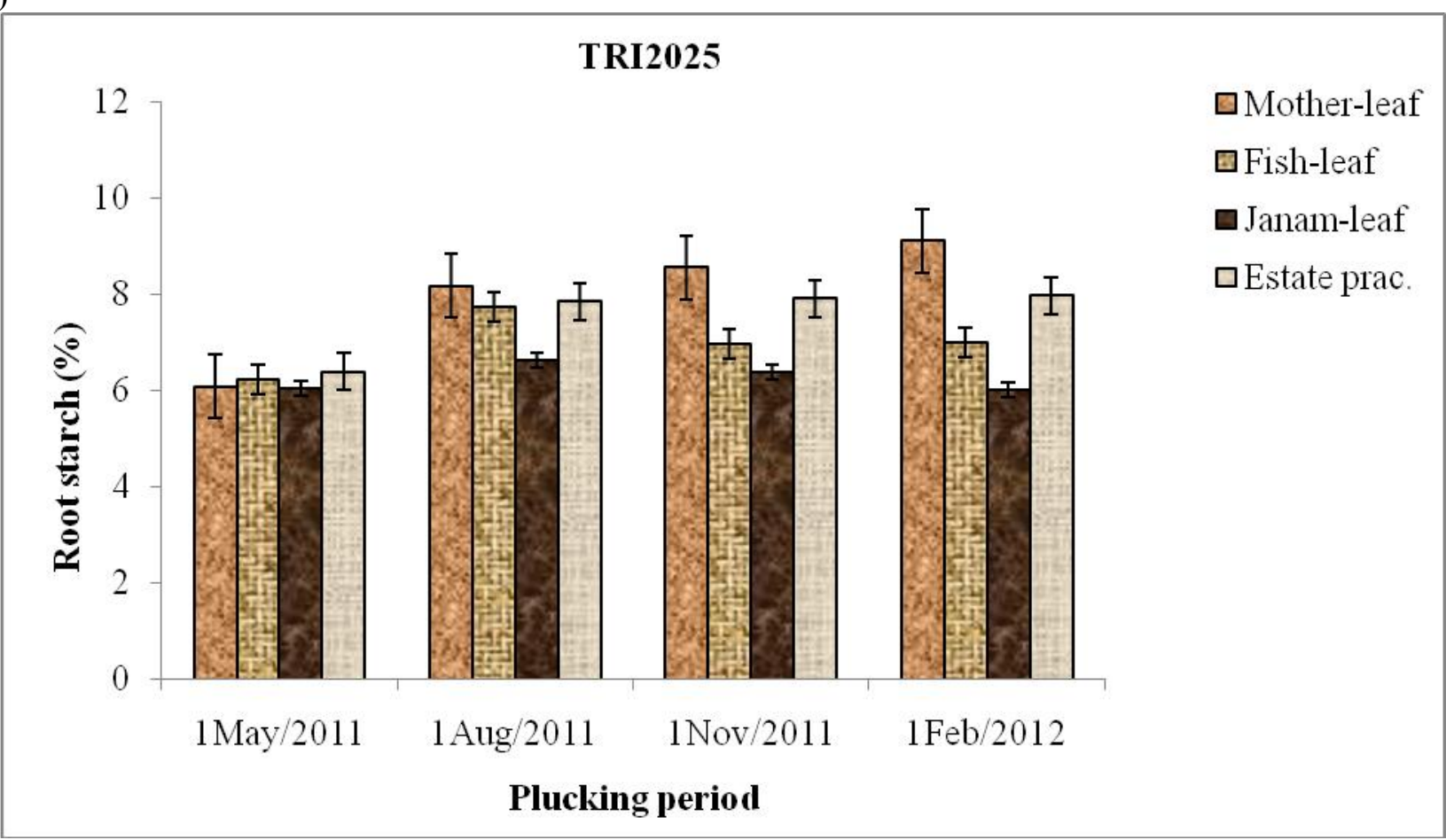

(b)

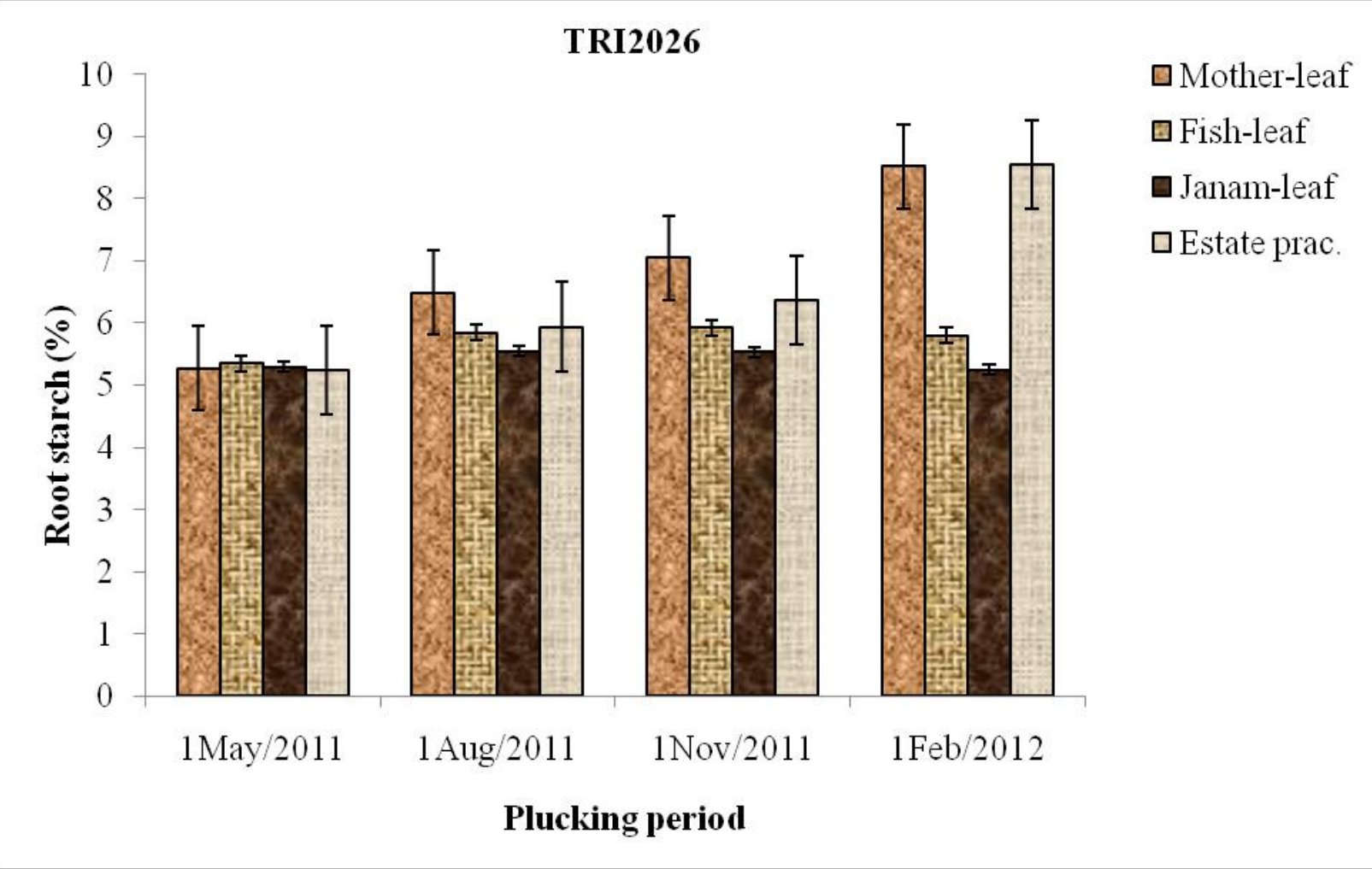

Fig. 3. Starch reserves of root for different levels of plucking in (a) TRI2025 and (b) TRI2026 at different plucking period

\section{Conclusions}

For getting the higher yield of tea, selection of the cultivar and appropriate plucking system are very important. Before pruning, normally it is suggested to follow the complete resting of tea bushes for about 1-2 months to increase the starch reserves of roots. From the present study, it is observed that mother-leaf plucking is an alternate option to increase the starch reserves of root before pruning. 


\section{Acknowledgements}

This work was supported by a grant from the National Agricultural Technology Project (NATP), Bangladesh Agricultural Research Council (BARC) and constitutes a part of a PhD training program. The authors are thankful to Mrs. P. Premathunga, TRI, Low Country Station, Ratnapura for her assistance during the measurement of root starch reserves.

\section{References}

De Costa, W. A. J. M.; Mohotti, A. J. and Wijeratne, M. A. 2007. Ecophysiology of tea. Brazilian Journal of Plant Physiology, 19(4): 299-332.

Green, M. J. 1965. Plucking experiment. Tea Research Institute of East Africa. Annual Report, pp. 52.

Krishnapillai, S.; Pallemulla, D. and Navaratne, S. 1992. Studies on tea and drought: Some observations on drought effects on physiology of tea. Sri Lanka Journal of tea Science, 61(2): 59-67.

Portsmouth, G. B. 1957. Factors affecting shoot production in tea (Camellia sinensis L.) when grown as a plantation crop. II. The influence of a climatic conditions and age from pruning on flush shoot production. Tea Quarterly, 28: 8-19.

Portsmouth, G. B. and Rajiah, E. S. 1957. Factors affecting shoot production in tea (Camellia sinensis L.) when grown as a plantation crop. III.
The time factor and new shoot production. Tea Quarterly, 28: 21-29.

Stephens, W. and Carr, M. K. V. 1994. Responses of tea (Camellia sinensis) to irrigation and fertilizer. IV. Shoot population density, size and mass. Experimental Agriculture, 30: 189- 205.

Tanton, T. W. 1992. Tea crop physiology. In: Willson, K.C. and Clifford, M.N. (Editors). Tea: Cultivation to Consumption. Chapman \& Hall, London.

Visser, T. 1960. Plucking practices in relation to maintenance foliage. Tea Quarterly, 31: 38-52.

Wettasinghe, D. T.; Nathaniel, R. K. and Kroon, D. D. 1981. Effect of severity of plucking on the and yield of low grown tea. Tea Quarterly, 50(3): 123-130.

Wickramaratne, M. R. T. 1981. Variation in some leaf characteristics in tea (Camellia sinensis L.) and their use in the identification of clones. Tea Quarterly, 50: $183-189$

Wijeratne, M. A. 1994. Effect of climatic factors on the growth of tea (Camellia sinensis L.) in the low country wet zone of Sri Lanka. PhD Thesis. University of London, Wye College, London.

Wijeratne, M. A. 2001. Shoot growth and harvesting of tea. Tea Research Institute of Sri Lanka, Talawakelle, Sri Lanka.

Wijeratne, M. A.; Premathunga, P. and Karunaratne, W. R. M. M. 2002. Variation of root starch reserves of tea and its impact on recovery after pruning. Journal of Plantation Crops, 30(1): 35-39. 